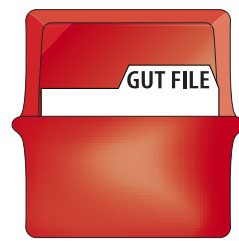

\title{
Collagenous colitis with mucosal tears on endoscopic insufflation: a unique presentation
}

Collagenous colitis (CC) is a clinicopathological syndrome of indeterminate aetiology, characterised by: (1) chronic watery diarrhoea and crampy abdominal pain and (2) thickened subepithelial collagen table and increased intraepithelial lymphocytes on histology. ${ }^{12}$ Gastrointestinal, radiographic, and endoscopic examinations are not diagnostic of CC. Endoscopically, the colorectal mucosa is usually normal, although some non-specific findings such as erythema or oedema have been reported in up to one third of cases.

\section{PATIENTS AND METHODS}

The endoscopic reports and medical records of each patient were reviewed, including prior colonoscopic examination reports. Two pathologists (MT, JHY) reviewed the patients' colorectal mucosal biopsies.

\section{RESULTS}

Three patients (two females aged 73 and 61 years; one male aged 62 years) were referred for evaluation of watery nonbloody diarrhoea (3-6xday) of 4-6 weeks' duration. All patients had their colonoscopy performed after standard bowel preparation (polyethylene glycol) and sedation (midazolam and meperidine). As the colonoscope was introduced into the bowel by experienced endoscopists (FWJ, FM), mucosal tears with bleeding, ranging from $1-10 \mathrm{~mm}$ in width and $5-40 \mathrm{~mm}$ in length, were noted following colonic insufflation with air (fig 1). These mucosal tears were found only in the right and transverse colon. The remainder of the colorectal

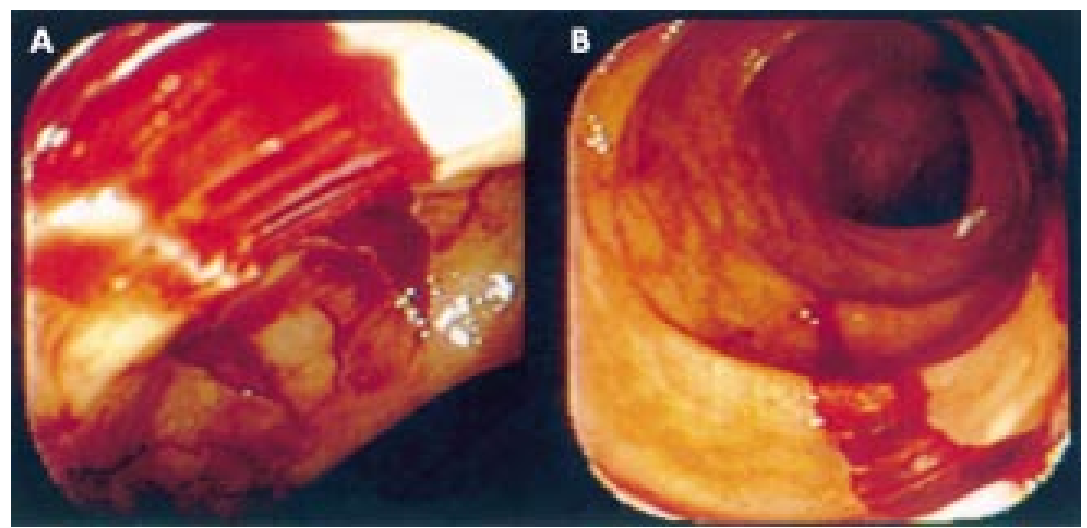

Figure 1 Colonoscopic images showing linear mucosal lacerations, measuring $1-5 \mathrm{~mm}$ in width and $1-4 \mathrm{~cm}$ in length in the right transverse $(A)$ and ascending colon (B). The muscularis mucosa was noted through some of these lacerations (A). mucosa was macroscopically normal on endoscopy. The histological findings in each case revealed CC with markedly thickened subepithelial collagen tables.

All three patients had hypothyroidism; laboratory results were essentially normal, except for a positive antinuclear antibody (1:160) in one patient. Cultures for stool pathogens and Clostridium diffcile toxin assay were negative.

Two patients responded to therapy with either tetracycline $(250 \mathrm{mg}$ orally three times daily) or oral mesalamine (Asacol $800 \mathrm{mg}$ three times daily) and had no diarrhoea 12-18 months later. However, one patient (61 year old female) continued to have diarrhoea, 2-4 times a day, after treatment with mesalamine, bismuth subsalicylate, ciprofloxacin, metronidazole, prednisone, and octreotide injections.

\section{DISCUSSION}

We have presented three patients with CC and endoscopic haemorrhagic lacerations on insufflation. Literature review revealed a case report of a patient with CC who showed multiple small haemorrhagic lacerations in the right colon. However, no case report has described the large longitudinal colonic mucosal lacerations seen in our cases. To our knowledge, similar haemorrhagic lacerations in the colon have not been described in any other gastrointestinal diseases. Gastrointestinal lacerations have been seen in the oesophageal and gastric mucosa only after cardiopulmonary resuscitation. ${ }^{4}$ From 1996 to 2000, approximately 100 patients with CC were

Hospital, Baltimore, Maryland 21287 , USA;
macruzco@jhsph.edu.
1 Bohr J, Tysk C, Eriksson S, et al. Collagenous
colitis: a retrospective study of clinical
presentation and treatment in 163 patients.
Gut 1996;39:846-51.
2 Lindstrom CG. Collagenous colitis with
watery diarrhea. A new entity? Pathol Eur
1976;1 1:87-9.
3 Richieri JP, Bonneau HP, Cano N, et al.
Collagenous colitis: an unusual endoscopic
appearance. Gastrointest Endosc
1993;39:192-6.
4 McDonnell PJ, Hutchins GM, Hruban RH, et
al. Hemorrhage form gastric mucosal tears
complicating cardiopulmonary resuscitation.
Ann Emerg Med 1984;13:230-3.
5 Cruz-Correa M, Giardiello FM. Collagenous
and lymphocytic colitis. In: Bayless TM,
Hanauer SB, eds. Advance therapy in
inflammatory bowel disease. Hamilton,
Canada: BC Decker Inc, 2001:631-3.

seen at our institution, and only three cases presented these findings.

A postulated mechanism for the mucosal lacerations in CC might be the rigid character of the collagen containing subepithelium, possibly in combination with endoscopic insufflation, leading to stretching of the mucosa and subsequent tearing. All three patients in our series presented with lacerations on the right colon where collagen deposits have been reported to be thickest. ${ }^{5}$

Although the most common endoscopic finding in CC is a normal mucosa, macroscopic lesions on endoscopy may be noted during colonic examination. In particular, the endoscopic finding of haemorrhagic lacerations in the right and transverse colon on insufflation should suggest a diagnosis of CC.

\section{ACKNOWLEDGEMENTS}

Supported by NIH Training Grant 2T32 DK07632-11 (MCC), NIH grant CA 53801, NIH Training Grant 2T32 DK07632-11, and 5P50 CA62924 (FMG).

M Cruz-Correa, F Milligan, F M Giardiello, T M Bayless, Department of Medicine, Johns Hopkins University School of Medicine, Meyerhoff Digestive Disease IBD Center, Baltimore, Maryland, USA

M Torbenson, J H Yardley,

Department of Pathology, Johns Hopkins University School of Medicine, Meyerhoff Digestive Disease IBD Center, Baltimore, Maryland, USA

Frank W Jackson, F Wilson Jackson, Jackson Gastroenterology, Camp Hill, Pennsylvania, USA

Correspondence to: M Cruz-Correa, 413 lock, 600 North Wolfe Street, Johns Hopkins (n) . 